UDC 81'373.45

DOI: $10.17223 / 24109266 / 9 / 5$

\title{
ROMANIZATION OF CHINESE HIEROGLYPHIC WRITING
}

\author{
Z.D. Kozelsky, Y.E. Kiselevich, T.V. Privorotskaya \\ National Research Tomsk State University (Tomsk, Russian Federation) \\ E-mail: kozelsky@sibmail.com; kisliy@sibmail.com; kutikova_t@mail.ru
}

\begin{abstract}
This article deals with the concept of Romanization of Chinese hieroglyphic writing, the reasons and motives for it, as well as its potential benefits for modern Chinese society. Various arguments in favor of Romanization and its positive impact on the development of the People's Republic of China are adduced. A conclusion is made on the significance of Romanization for different spheres of Chinese society.

Keywords: Romanization; China; Chinese language; hieroglyphic writing.
\end{abstract}

\section{Introduction}

Chinese has always been seen as one of the most difficult languages to learn. For the most part it was due to its writing system, which is logographic. The symbols of logographic systems present the words themselves words are not made up of various letters as in alphabetic systems [1]. This system is not only hard to learn per se, but also because it is utterly different from the familiar Latin or Cyrillic script.

China is a country with a 5000-year history and a culture considered to be unique and one of the most ancient in the world [2]. The seeming inaccessibility of the language made the culture seem inaccessible, and lack of cultural knowledge made it hard to understand the people, which affected China as a country on the global level for a long time. China was always somewhat isolated in terms of economic, political and cultural interaction, which caused some hardship to the country, and which, as we can infer, was always partially because of the language, and especially the writing system, and at some point in the twentieth century the Chinese started to realize that and made attempts to change the writing system in some way.

China's defeat in the Opium wars, as well as the Second SinoJapanese war demonstrated the country's weakness and technical disadvantage [3]. The time before the revolution of 1911 can be seen as a time of uncertainty in China. There were many predictions about the ways of the country's further development in China itself, as well as abroad. The problems of language were as serious as many other issues, first of all, two closely connected ones: the problem of literary language and the problem of the writing system.

That situation was typologically very reminiscent of the one encountered by many civilizations at a certain stage of their development. Through- 
out many centuries Latin, Greek, Church Slavonic, Classical Japanese (Bungo), Classical Arabic, etc. were the languages of world culture [4].

Chinese was not on that list because it was solely the language of Chinese culture. The traditional Chinese characters and writing system were very hard to learn, hence the language's inability to become a language of world culture.

V.M. Alekseyev points to the destruction of the traditional system in his book Chinese Hieroglyphic Writing and its Romanization. In 1905 "the abolition of the classical education system and state exams as the only way of starting a career in the government breached the hieroglyphic foundation and signified the beginning of its fall" [5: 57]. The main motives for the Romanization of Chinese writing were political.

\section{The political motives for Romanization}

The main parties that participated in discussing the question of changing traditional Chinese language:

- "The Radicals", who brought forward the proposal to replace Chinese with some Western language or Esperanto.

- "The Phonetic Transcription party" that wanted to continue using the Chinese language, but replace the hieroglyphic writing system with a new one based on European languages.

- "The Pedagogue party", who had ideas similar to those of "The Phonetic Transcription party", but planned to implement them differently.

- "The Neoclassical party" that wanted to keep using the hieroglyphic writing, but modernize the language by means of its partial simplification.

- "The Conservative party", which spoke in favor of continued use of the traditional Chinese hieroglyphic writing system and stood against any changes.

In China there were arguments between those who wanted the country to have only one standard language and those who wanted there to be a standard variety that would include standardized versions of all main dialects. Almost everyone, with the exception of the most devoted conservatives, understood that a "hieroglyphic language" was not suitable for modern life [5: 11]. It is worth noting that in the early 1950s, during a discussion of problems of the alphabet in China, a project of replacing the hieroglyphic writing system with a Cyrillic alphabet emerged, but even then the only project that was taken into serious consideration was the Romanization project, which was later rejected as well due to major contradictions between the parties [6].

\section{The main contradictions}

- Those who were for Romanization based their opinions on the fact that Chinese characters are connected to the old federal culture and the obso- 
lete "hieroglyphic language", which obstructed China's development. In addition to that, the difficulty of the Chinese writing system required a longer period of education. That was the way in which many Chinese citizens (and not only communists), as well as the majority of foreigners, thought.

- Those who were against Romanization before all other things cared about preserving the millennia-old traditions. They rejected any changes because they could harm the national identity, as well as affect the development of the country.

V.M. Alekseyev mentions that previously "you could travel all across China with its many dialects possessing only the knowledge of the commonly used (especially in the phonetic compromise) so-called 'Mandarin' dialect" [5: 11]. It meant that people of different provinces spoke structurally different languages that had a common foundation, which impeded communication with foreigners who studied only a specific dialect, as well as one's compatriots. Because of this the norms of a new standard language one could use to speak and write began to develop. There was the term "Putonghua" (literally "the common speech"), which was eventually adopted by the People's Republic of China to refer to the standardized language. The language was connected with both the hieroglyphic writing and Latin script, which did not contradict the neoclassicals' views.

V.M. Alekseyev wrote in favor of a common language: "Later they will say that a person from Sichuan Province, who was taught in his dialect and who got acquainted with the English language during his education, will be more a citizen of the world, than a citizen of China, to which, in the absence of hieroglyphic writing, nothing can connect him" [Ibid.: 53-54].

A famous Chinese revolutionary poet Xiao San wrote in his article "The Romanization of Chinese writing" that Chinese hieroglyphic writing is nothing but an archaic vestige of the ancient feudalism, a symbol of the centuries of slavery, a weapon of enslavement of the working masses used by the ruling class. "Characters are an obstacle to raising the political and cultural level of the workers and the peasants of China, and only the revolutionary proletariat and peasantry masses will revolutionize Chinese writing," he said [7: 34].

"Mandarin" could not be seen as a native language for the majority of Chinese people, it could not be forced upon them, just as non-Russian citizens of the USSR could not be forced, as it was believed at that time, to speak Russian [5: 61]. Thus, the common language still was divided into different dialects. The only thing left to do was to develop a unified writing system, which would serve as the foundation for all the provincial dialects.

In reality, there were only two possibilities: to keep the characters (unchanged or reformed) and to Romanize the writing. Attempts were made to reform the writing based on the principles of Japanese Kana, but, since the political motives were dominant, that was rejected due to contentious relations between China and Japan and anti-Japanese propaganda [7: 34]. 
The development of the "Pinyin" system began in the period following the founding of the People's Republic of China in 1949. It was approved and adopted by the PRC's government in 1958. In 1982 the Pinyin system was adopted by ISO, which allowed China to reach a higher position in international relations [8].

\section{The positive aspects of the Romanization; the usage of Pinyin in modern-day China}

Despite many contradictions, most of the arguments were proRomanization, partly because Chinese hieroglyphic writing had more problems than benefits.

\section{The main problems of traditional Chinese writing:}

1. The vast number of characters.

2. The complexity of the characters.

3 . The characters are hard to memorize.

4. The characters are hard to learn.

5. The archaic nature of the characters.

6. The inconvenience for transcribing human speech.

The problems of Chinese hieroglyphic writing led Europeans to "abruptly isolate themselves from Chinese culture in general, and from its written culture as well, leaving it 'behind the Great Wall of China', they viewed the culture of China as fundamentally alien to their spirit and comprehension, unapproachable and not meant to be approached" [5: 5-6]. Therefore, the Chinese government and linguists had to build such a writing system, which would not be a barrier between the East and the West.

Even though the Chinese writing system had many problems, hieroglyphic writing had some positive aspects that needed to be taken into consideration whilst reforming the writing.

The positive aspects of the Chinese hieroglyphic writing system:

1. Written words take up much less space compared to alphabetic writing.

2. It is possible to guess the character's meaning based on its graphical form.

3. The characters are strictly structured, which makes the process of memorizing them easier.

\section{The convenience of Pinyin}

One character is one syllable. There are a limited number of syllables in the Chinese language. There are a total of around 320 syllables, and if one knows how to pronounce all of them, they know how to pronounce every word in the Chinese language. The system includes Latin script- 
interpretations of the pronunciation of every character-syllable. Every syllable consists of the beginning part - the initial (a consonant), and the ending part - final (a vowel or a combination of a vowel and a consonant, or a combination of two or three vowels). There are a total of 21 initials and 36 finals in Chinese language, different combinations of which form all the syllables.

Examples of Pinyin transcription:

中国 - zhōng guó - China (literally “central state");

汉语 - hàn yŭ - Chinese language (literally "the language of the Han dynasty");

北京 - běi jīng - Beijing (literally “the northern capital");

上海 - shàng hăi - Shanghai (literally “on the sea");

风水 - fēng shuǐ - Feng shui (literally “wind and water”).

Pinyin is significant to contemporary China; the system is used in many spheres of Chinese society.

\section{Spheres of usage of Pinyin:}

1. In everyday life: street name plates and metro station plates use Pinyin to make city orientation in cities easier for both Chinese and foreigners.

2. In mobile phones and computers Pinyin is used to type Chinese characters (the user types in the transcription and chooses the needed character from the list).

3. In dictionaries, reference and study books.

4. In mass media, proper nouns and the names of ethnic minorities are written using Pinyin.

\section{Conclusion}

In conclusion, the Romanization of Chinese hieroglyphic writing made it easier for people of other countries to study the Chinese language, which breached the inaccessibility of Chinese culture for people who speak other languages. Language and culture are closely related to each other. It is quite a difficult task to feel a language and the way of thinking of its native speakers. At the same time it is the only way to understand those people whose language one studies, and avoid some certain misunderstandings which are the natural result of the studying of a foreign culture. This happens because we are the representatives of some particular culture and, whatever we do, our language and our culture make us think in a certain way, determining our thoughts, even when we are in the process of acquiring knowledge and understanding of some another culture [9]. When it became easier to study the language and the culture, it became easier to understand the people, which improved China's relations with European countries, and 
its position on the list of world cultures. It also improved the overall quality of education in China, since it helped students who speak different dialects understand each other, teachers, study books, etc.

\section{References}

1. Zarubin A., Mitchell P.J. (2013). English in China: English vs. Chinglish, Culture vs Language. Saarbruecken: LAP LAMBERT.

2. Mitchell P.J., Zarubin A.N. (2012). The English language internationally: an introduction to the case of China. Tomsk, Language and Culture. Collection of articles of XXII international academic conference. pp. 14-20.

3. Tikhonova E.V., Korneva E.D. (2015). The spread of English language in China. Kazan, Young scientist. 19. pp. 702-705.

4. Polivanov E.D. (1968). Selected works. Articles on General Linguistics. Moscow: Science.

5. Alekseyev V.M. (1932). Chinese hieroglyphic writing and its Romanization. Leningrad: the Academy of Sciences of the USSR.

6. Datsyshen E.D. (2008). The movement for the Romanization of Chinese writing and development of Chinese studies in the Soviet Far East. Vladivostok, Russia and the APR. 3. pp. 160-169.

7. Konrad N.I. (1972). The West and the East (articles). Moscow: Science.

8. Chinese Translation Centre (2014). The "Pinyin" system in modern communication. URL: $\mathrm{http}: / /$ chinese-center.ru/publications/?publications $=23$

9. Mitchell P.J., Zarubin A.N. (2013). Chinglish: a cultural phenomenon. Tomsk, Vestnik of Tomsk State University. 374. pp. 69-80.

Resived 02.05.2017

\section{Information about the authors:}

Kozelsky Zahar - student, Department of Chinese, Faculty of Foreign Languages, National Research Tomsk State University (Tomsk, Russian Federation). E-mail: kozelsky@sibmail.com

Kiselevich Yan - student, Department of Chinese, Faculty of Foreign Languages, National Research Tomsk State University (Tomsk, Russian Federation). E-mail: kisliy@sibmail.com Privorotskaya Tatyana - lecturer, Department of Chinese, Faculty of Foreign Languages, National Research Tomsk State University (Tomsk, Russian Federation). E-mail: kutikova_t@mail.ru 